\title{
Methylenetetrahydrofolate Reductase (MTHFR) Gene Mutations in Patients with Idiopathic Scoliosis: A Clinical Chart Review
}

\author{
Mark W. Morningstar ${ }^{1 *}$, Megan N. Strauchman1, Clayton J. Stitzel2 ${ }^{2}$ Brian Dovorany3, \\ Aatif Siddiqui ${ }^{4}$
}

\author{
${ }^{1}$ Natural Wellness \& Pain Relief Center, Grand Blanc, MI, USA \\ ${ }^{2}$ Lancaster Spinal Health Center, Lititz, PA, USA \\ ${ }^{3}$ Posture \& Spine Care Center, Green Bay, WI, USA \\ ${ }^{4}$ Esprit Wellness, New York, NY, USA \\ Email: *drmorningstar@nwprc.com
}

How to cite this paper: Morningstar, M.W., Strauchman, M.N., Stitzel, C.J., Dovorany, B. and Siddiqui, A. (2017) Methylenetetrahydrofolate Reductase (MTHFR) Gene Mutations in Patients with Idiopathic Scoliosis: A Clinical Chart Review. Open Journal of Genetics, 7, 62-67.

https://doi.org/10.4236/ojgen.2017.71006

Received: January 9, 2017

Accepted: March 27, 2017

Published: March 30, 2017

Copyright $\odot 2017$ by authors and Scientific Research Publishing Inc. This work is licensed under the Creative Commons Attribution International License (CC BY 4.0).

http://creativecommons.org/licenses/by/4.0/

\begin{abstract}
The effects of genetic variations of methylenetetrahydrofolate reductase (MTHFR) enzyme activity have been the discussion of many research papers. It has been associated with multiple neurological sequelae, and has been implicated in other chronic diseases. Although many genetic influences on the development and/or progression of idiopathic scoliosis have been reported, there has been no report of any relationship between MTHFR mutations and idiopathic scoliosis. This paper compared two groups of patients who received MTHFR genetic testing. One group had a history of idiopathic scoliosis, while the other served as a control group. The scoliosis group showed a positive MTHFR mutation in 23 out of 44 patients, while the control group showed $11 / 44(\mathrm{P}<0.01)$. Given the increased incidence of MTHFR defects in scoliosis patients, this study warrants further investigation into how MTHFR variations may trigger the development or progression of idiopathic scoliosis.
\end{abstract}

\section{Keywords}

Genetics, MTHFR, Polymorphism, Methylation, Scoliosis, Spine

\section{Introduction}

Recent medical literature has seen demonstrated a substantially increased interest in genetic testing for predicting various diseases, as well as to evaluate the functionality of various metabolic pathways. For example, one of the most studied single nucleotide polymorphisms (SNPs) is the methylenetetrahydrofolate reductase (MTHFR) enzyme. MTHFR gene variations have been associated with 
ADHD [1], autism [2], cataract [3], colon cancer [4], glioma or meningioma [5], methotrexate toxicity [6], and migraines [7].

Idiopathic scoliosis is a curvature of the spine involving a 3-dimensional displacement measuring at least 10 degrees [8]. Evidence [9] suggests that there are multiple potential associations between specific genetic [10], neurological [11], and/or endocrine [12] variations that may lead to the cause, or progression of, idiopathic scoliosis. Although reduction in MTHFR activity has been linked to other health conditions, it has not been studied in patients with idiopathic scoliosis. Given that methylation is responsible for many enzymatic conversions along several hormone pathways, including the melatonin pathway [13], it is postulated that alterations of the genes responsible for encoding MTHFR activity may somehow be associated with scoliosis. This is in light of the fact that melatonin deficiency [14] and melatonin signaling abnormalities [15] have been previously implicated in scoliosis etiology.

Single nucleotide polymorphisms of the 677CT and 1298AC alleles cause a decrease in MTHFR enzyme activity. [16]. A homozygous mutation (677TT) of the 677CT allele has been shown to result in a decrease in MTHFR enzyme activity by $60 \%$ [17], while a heterozygous mutation of both alleles can also cause a $50 \%-60 \%$ reduction in MTHFR activity. [18]. The purpose of this paper was to evaluate the presence of any MTHFR gene variants in a group of patients with idiopathic scoliosis (IS) patients compared to patients who did not have idiopathic scoliosis.

\section{Materials and Methods}

Patient charts at a private medical clinic were reviewed for those patients who presented with scoliosis. These patients had been given an option to receive genetic testing. Testing was performed via blood, saliva collection or buccal swab, depending upon other concomitant lab work ordered. To minimize specimen collection per patient, the specimen required for other concurrent lab studies was also selected for genetic analysis. Genetic testing was focused on the status of the MTHFR genes, specifically looking at 677CT and 1298AC. For purposes of this study, only the charts of those patients with idiopathic scoliosis were selected. Patients with a history of neuromuscular, syndromic, or congenital scoliosis were excluded. Past treatment history in patients with idiopathic scoliosis was irrelevant and not considered. Based upon these criteria, a total of 44 patient charts were consecutively selected.

Once these patient charts had been identified, an additional set of 44 patient charts was selected. These charts contained information on patients who presented to the same medical clinic, also had genetic testing performed, but did not have any type of scoliosis in their history. This group of charts served as the control group. Once all files were selected, patients whose files were chosen gave their written informed consent to use their non-identifying information. For both groups, the MTHFR gene results were analyzed. Patients would be considered positive for an MTHFR variation if they had one of the following results: 
1) a double mutation of either the 677 or 1298 allele (hereafter referred to as homozygous positive), or 2) a single mutation in both alleles (hereafter referred to as heterozygous positive). These results were obtained for all patients in each group, and then compared quantitatively and qualitatively to the other group. Patients in both groups whose charts were selected subsequently provided written permission to use their non-identifying lab results and demographics.

\section{Results}

When comparing the total sample size of each group to one another, the scoliosis group was positive for an MTHFR mutation in 23 out of 44 cases (52\%). The control group was positive in 11 of 44 cases (25\%). Figure 1 provides an illustration of this data.

It was also of interest to evaluate the incidence of MTHFR mutations when considering ethnicity. In the scoliosis group, 3 of the 23 positive patients were African-American, 1 was Hispanic, and 1 was Indian. The remaining 18 positive patients were Caucasian. Given a total of 37 total Caucasian scoliosis patients, this makes the incidence of MTHFR defect among this ethnicity to be $49 \%$. In the control group, 8 Caucasians, 2 African-Americans, and 1 Hispanic patient were MTHFR positive, while 2 Indian patients and 1 Hispanic patient were negative. The remaining 38 patients were Caucasian, resulting in an incidence of $21 \%$. Table 1 provides a summary of these results.

With a 99\% confidence interval, the data were compared using independent t-tests. These results are shown in Table 2. When examining specific genotypes of each gene, the 677CT/TT genotypes were not statistically different between patient groups. However, the 1298AC/CC genotypes were significantly higher in the scoliosis groups compared to the control group $(\mathrm{P}<0.01)$. The heterozygous

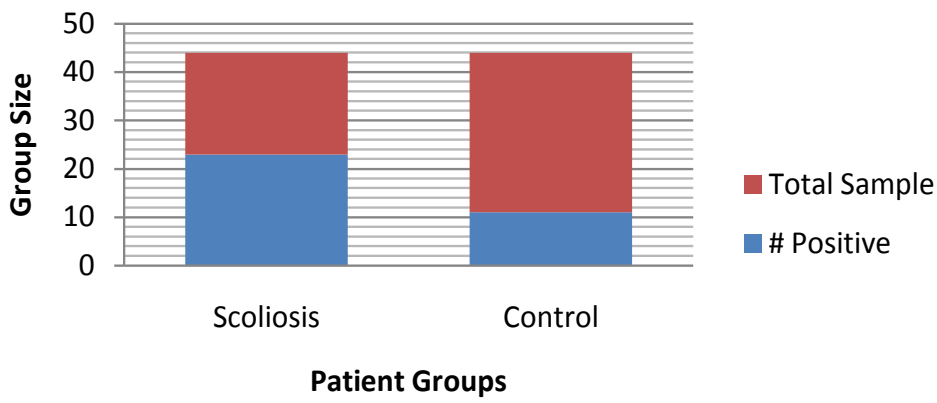

Figure 1. Frequency of heterozygous and homozygous positive genotypes. Positive genotypes in scoliosis were statistically significant at $\mathrm{P}<$ $0.01(0.002924)$.

Table 1. Frequency of 677CT genotypes in IS and control groups.

\begin{tabular}{|c|c|c|c|}
\hline $677 \mathrm{CT}$ & CC (normal) & CT (heterozygosity) & TT (homozygosity) \\
\hline Scoliosis & 26 & $13^{*}$ & $5^{*}$ \\
\hline Control & 31 & 9 & 4 \\
\hline
\end{tabular}


Table 2. Frequency of 1298AC genotypes in IS and control groups.

\begin{tabular}{cccc}
\hline 1298AC & AA (normal) & AC (heterozygosity) & CC (homozygosity) \\
\hline Scoliosis & 25 & $13^{*}$ & $6^{*}$ \\
Control & 36 & 6 & 2 \\
\hline
\end{tabular}

${ }^{\star}$ Combined occurrence was statistically significant at $\mathrm{P}<0.01(0.007257)$.

mutation occurred over twice as often, and the homozygous mutations occurred three times more than in the control group.

\section{Discussion}

The data demonstrate that MTFHR polymorphisms are found significantly more frequently in patients with idiopathic scoliosis when compared with non-scoliotic patients. It is unlikely, however, that MTHFR variants are causative for scoliosis, given that a notable minority of non-scoliotic patients also carry these polymorphisms. This is the first investigation into the MTHFR genetic variation of the A1298C allele in patients with idiopathic scoliosis. Genetic variations of the A1298C allele may reduce tetrahydrobiopterin (BH4), which serves as a cofactor for phenylalanine hydroxylase (PAH), tyrosine hydroxylase (TH), and tryptophan hydroxylase (TPH) [19]. These enzymes are required to produce serotonin and the catecholamines. Morningstar et al. [20] have previous identified neurotransmitter imbalances in a cohort of patients with adolescent idiopathic scoliosis compared to age-matched controls. Moreover, when these neurotransmitter imbalances were corrected, scoliosis correction was improved compared to scoliotic controls [21].

It is possible that there could be other genetic variants occurring simultaneously in patients with idiopathic scoliosis, thus increasing the chance of developing the spinal deformity. Alternatively, there may also be environmental factors at play affecting idiopathic scoliosis patients that are not affecting nonscoliotics. The non-scoliotics may also not be exposed to the same environmental factors contributing to the IS onset.

\section{Limitations}

This study does not account for the downstream influences of MTHFR variants on neurotransmitter metabolism. For example, methylation is required to convert norepinephrine into epinephrine [22], and is also important in the negative feedback loop in serotonin metabolism [23]. Morningstar et al have previously described the role of these neurotransmitters in reflexive postural control [24], which is often altered in the majority of patients with IS [25]. However, it is likely that there are different gradations of downstream activity, possibly dependent upon the patient's current lifestyle and dietary habits, and local environmental factors. Therefore, investigation into these aspects in this patient population is warranted.

\section{Conclusion}

When comparing two small clinical samples of patient charts, $52 \%$ of patients 
with a history of idiopathic scoliosis tested positive for an MTHFR genetic variation while only $25 \%$ of non-scoliotics tested positive. Given the impact that the methylation cycle has on neurotransmitter metabolism, this study may help to foster further investigation into this impact relative to neuromotor control of postural reflex pathways. It is currently unknown how their interaction may be associated with the development or progression of idiopathic scoliosis.

\section{References}

[1] Gokcen, C., Kocak, N. and Pekgor, A. (2011) Methylenetetrahydrofolate Reductase Gene Polymorphisms in Children with Attention Deficit Hyperactivity Disorder. International Journal of Medical Sciences, 8.

[2] Boris, M., Goldblatt, A., Galanko, J. and James, S.J. (2004) Association of MTHFR Gene Variants with Autism. Journal of the American Physicians and Surgeons, 9, 106-108.

[3] Wang, X., Qiao, C., Wei, L., Han, Y., Cui, N., Huang, Z., Li, Z., Zheng, F. and Yan, M. (2015) Associations of Polymorphisms in MTHFR Gene with the Risk of AgeRelated Cataract in Chinese Han Population: A Genotype-Phenotype Analysis. PLoS ONE, 10, e0145581. https://doi.org/10.1371/journal.pone.0145581

[4] Cao, H.-X., Gao, C.-M., Takezaki, T., Wu, J.-Z., Ding, J.-H., Liu, Y.-T., Li, S.-P., et al. (2008) Genetic Polymorphisms of Methylenetetrahydrofolate Reductase and Susceptibility to Colorectal Cancer. Asian Pacific Journal of Cancer Prevention, 9, 203-208.

[5] Bethke, L., Webb, E., Murray, A., Schoemaker, M., Feychting, M., Lonn, S., Ahlbom, A., et al. (2008) Functional Polymorphisms in Folate Metabolism Genes Influence the Risk of Meningioma and Glioma. Cancer Epidemiology, Biomarkers \& Prevention, 17, 1195-1202. https://doi.org/10.1158/1055-9965.EPI-07-2733

[6] Fisher, M.C. and Cronstein, B.N. (2009) Meta-Analysis of Methylenetetrahydrofolate Reductase (MTHFR) Polymorphisms Affecting Methotrexate Toxicity. Journal of Rheumatology, 36, 539-545. https://doi.org/10.3899/jrheum.080576

[7] Liu, A., Menon, S., Colson, N.J., Quinlan, S., Cox, H., Peterson, M., Tiang, T., et al. Analysis of the MTHFR C677T Variant with Migraine Phenotypes. BMC Research Notes, 3, 213. https://doi.org/10.1186/1756-0500-3-213

[8] Miller, N.H. (2011) Idiopathic Scoliosis: Cracking the Genetic Code and What Does It Mean? Journal of Pediatric Orthopaedics, 31, S49-S52. https://doi.org/10.1097/BPO.0b013e318202bfe2

[9] Porter, R.W. (2001) The Pathogenesis of Idiopathic Scoliosis: Uncoupled NeuroOsseous Growth? European Spine Journal, 10, 473-481.

https://doi.org/10.1007/s005860100311

[10] Moreau, A., Wang, D.S., et al. (2004) Melatonin Signaling Dysfunction in Adolescent Idiopathic Scoliosis. Spine, 29, 1772-1781. https://doi.org/10.1097/01.BRS.0000134567.52303.1A

[11] Burwell, R.G., Clark, E.M., Dangerfield, P.H. and Moulton, A. (2016) Adolescent Idiopathic Scoliosis (AIS): A Multi-Factorial Cascade Concept for Pathogenesis and Embryonic Origin. Scoliosis and Spinal Disorders, 11, 8. https://doi.org/10.1186/s13013-016-0063-1

[12] Wajchenberg, M., Astur, N., Kanas, M. and Martins, D.E. (2016) Adolescent Idiopathic Scoliosis: Current Concepts on Neurological and Muscular Etiologies. Scoliosis and Spinal Disorders, 11, 4. https://doi.org/10.1186/s13013-016-0066-y 
[13] Lee, H.Y., Byeon, Y., Lee, K., Lee, H.J. and Back, K. (2014) Cloning of Arabidopsis Serotonin N-Acetyltransferase and Its Role with Caffeic Acid O-Methyltransferase in the Biosynthesis of Melatonin in Vitro Despite Their Different Subcellular Localizations. Journal of Pineal Research, 57, 418-426. https://doi.org/10.1111/jpi.12181

[14] Machida, M., Dubousset, J., Yamada, T. and Kimura, J. (2009) Serum Melatonin Levels in Adolescent Idiopathic Scoliosis Prediction and Prevention for Curve Progression-A Prospective Study. Journal of Pineal Research, 46, 344-348. https://doi.org/10.1111/j.1600-079X.2009.00669.x

[15] Man, G.C., Wang, W.W., Yim, A.P., Wong, J.H., Ng, T.B., Lam, T.P., Lee, S.K., Ng, B.K., Wang, C.C., Qiu, Y. and Cheng, C.Y. (2014) A Review of Pinealectomy-Induced Melatonin-Deficient Animal Models for the Study of Etiopathogenesis of Adolescent Idiopathic Scoliosis. International Journal of Molecular Sciences, 15, 16484-16499. https://doi.org/10.3390/ijms150916484

[16] Chango, A., Boisson, F., Barbe, F., et al. (2000) The Effect of 677CT and 1298AC Mutations on Plasma Homocysteine and 5,10-Methylenetetrahydrofolate Reductase Activity in Healthy Subjects. British Journal of Nutrition, 83, 593-596. https://doi.org/10.1017/S0007114500000751

[17] Weisberg, I., Tran, P., Christensen, B., Sibani, S. and Rozen, R. (1998) A Second Genetic Polymorphism in Methyltetrahydrofolate Reductase (MTHFR) Associated with Decreased Enzyme Activity. Molecular Genetics and Metabolism, 64, 159-172. https://doi.org/10.1006/mgme.1998.2714

[18] Rady, P.L., Szucs, S., Grady, J., et al. (2002) Genetic Polymorphisms of Methylenetetrahydrofolate Reductase (MTHFR) and Methionine Synthasereductase (MTRR) in Ethnic Populations in Texas: A Report of a Novel MTHFR Polymorphic Site, G1793A. American Journal of Medical Genetics, 107, 162-168. https://doi.org/10.1002/ajmg.10122

[19] Werner, E.R., Blau, N. and Thony, B. (2011) Tetrahydrobiopterin: Biochemistry and Pathophysiology. Biochemical Journal, 438, 397-414. https://doi.org/10.1042/BJ20110293

[20] Morningstar, M. (2013) Neurotransmitter Patterns in Patients with Adolescent Idiopathic Scoliosis (AIS). Scoliosis, 8, O1. https://doi.org/10.1186/1748-7161-8-S2-O1

[21] Morningstar, M.W., Siddiqui, A., Dovorany, B. and Stitzel, C.S. (2014) Can Neurotransmitter Status Affect the Results of Exercise-Based Scoliosis Treatment? Results of a Controlled Comparative Chart Review. Alternative \& Integrative Medicine, 3 , 177.

[22] Pohorecky, L.A., Zigmond, M., Karten, H. and Wurtman, R.J. (1969) Enzymatic Conversion of Norepinephrine to Epinephrine by the Brain. Journal of Pharmacology and Experimental Therapeutics, 165, 190-195.

[23] Hensler, J. (2006) Serotonin. In: Siegel, G.J., Albers, R.W., Brady, S.T. and Price, D.L., Eds., Basic Neurochemistry: Molecular, Cellular, and Medical Aspects, Elsevier Academic Press, Burlington.

[24] Morningstar, M.W. (2016) Neurotransmitter Status and Idiopathic Scoliosis: A Commentary on Pathways, Testing, Clinical Utility, and Treatment. Current Pediatric Research, 20, 14-19.

[25] Pialasse, J.P., Mercier, P., Descarreaux, M. and Simoneau, M. (2016) Sensorimotor Control Impairment in Young Adults with Idiopathic Scoliosis Compared with Healthy Controls. Journal of Manipulative and Physiological Therapeutics, 39, 473479. https://doi.org/10.1016/j.jmpt.2016.06.001 
Submit or recommend next manuscript to SCIRP and we will provide best service for you:

Accepting pre-submission inquiries through Email, Facebook, LinkedIn, Twitter, etc. A wide selection of journals (inclusive of 9 subjects, more than 200 journals)

Providing 24-hour high-quality service

User-friendly online submission system

Fair and swift peer-review system

Efficient typesetting and proofreading procedure

Display of the result of downloads and visits, as well as the number of cited articles Maximum dissemination of your research work

Submit your manuscript at: http://papersubmission.scirp.org/

Or contact ojgen@scirp.org 